\title{
A Novel Survey of the Treatment Trends and Technical Details for Extracorporeal Shockwave Lithotripsy From Experienced European Endourologists
}

\author{
(1) Serkan Yenigürbüz, (1) Caner Ediz, (1) Cumhur Yeşildal, (1) Mehmet Pehlivanoğlu, (1) Yunus Emre Kızılkan, \\ (D) Hasan Hüseyin Tavukçu, (D) Ömer Yılmaz \\ University of Health Sciences Turkiye, Hamidiye Faculty of Medicine; Istanbul Sultan 2. Abdülhamid Han Training and Research Hospital, Clinic of \\ Urology, Istanbul, Turkiye
}

What's known on the subject? and What does the study add?

Guideline recommendations on shockwave lithotripsy (SWL) are well known. In terms of the practical application of SWL, no such study has been published in Europe before. We share our results with this survey study.

\begin{abstract}
Objective: This study aimed to evaluate the practice of extracorporeal shockwave lithotripsy (ESWL) treatment from different aspects (indications, technical, and equipment-related characteristics) through a questionnaire response by the experienced endourologist in the European centers.

Materials and Methods: A survey of 72 questions on four main topics was prepared by our team to evaluate the demographics of technical equipment, treatment applications, and pretreatment preparations. The survey was mailed to 200 endourologists, of whom 97 academic endourologists enrolled, $75 \%$ of them were from university or training hospitals and 69\% have experience of $>10$ years in urology.

Results: Of the urologist, 74\% had direct access to ESWL-device, and the endourologist was mainly responsible for the ESWL unit with the 61\% rate and was secondly the technician, which was trained on ESWL (25\%). The factors that affect the decision for ESWL include the stone's size, location, density, composition, and kidney anatomy. Stone density was the most preferred for the ESWL decision and the cut-off value was $<1000$ hounsfield unit for the $71 \%$ of endourologists. Increased oral hydration and medical expulsive treatments were commonly used and recommended after the ESWL session. Routine antibiotic prophylaxis was not used by most of the endourologists (45\%), and ureteroscopy (39\%) was the most responded approach after steinstrasse formation.

Conclusion: Survey answers revealed that most of the experienced European endourologists decide to treatment alternatives following the suggested guidelines and ESWL is still a valuable option for urinary stone treatment.
\end{abstract}

Keywords: Extracorporeal shockwave lithotripsy, europe, survey

\section{Introduction}

Urolithiasis is a common problem in Europe, with an estimated prevalence of 5-9\% (1). Extracorporeal shockwave lithotripsy (ESWL) has been introduced as the only non-invasive treatment modality for urolithiasis at the beginning of the 1980s and continued as the most popular option until lasers and flexible ureteroscopic instruments were available as minimal invasive stone management (2). The treatment concepts of upper urinary tract stones have rapidly changed in the last two decades, and as stated in a well-conducted study, flexible ureterorenoscopic stone management has become popular with an increase in the application (103\%) in a 5-year study period (2009-2015), while the use of ESWL remained stable or decreased to a certain extent.

Correspondence: Serkan Yenigürbüz MD, University of Health Sciences Turkiye, Hamidiye Faculty of Medicine; İstanbul Sultan 2. Abdülhamid Han Training and Research Hospital, Clinic of Urology, istanbul, Turkiye

Phone: +90 5055717480 E-mail: serkanyenigurbuz@gmail.com ORCID-ID: orcid.org/0000-0002-4862-2103

Received: 05.06.2021

Accepted: 19.09.2021

Cite this article as: Yenigürbüz S, Ediz C, Yeşildal C, Pehlivanoğlu M, Kızılkan YE, Tavukçu HH, Yılmaz Ö. A Novel Survey of the Treatment Trends and Technical

Details for Extracorporeal Shockwave Lithotripsy From Experienced European Endourologists. J Urol Surg, 2022;9(1):33-39.

๑Copyright 2022 by the Association of Urological Surgery / Journal of Urological Surgery published by Galenos Publishing House. 
(3). The possible reason is the more unfavorable conditions for ESWL including shock wave resistant stones, steep infundibular pelvic angles, long lower pole calyx, narrow infundibulum, and long skin-to-skin distance. The literature review revealed that complication rates between ESWL and retrograde intrarenal surgery were not effective in treatment modality selection $(4,5)$.

The European Association of Urology (EAU) Guidelines still recommends SWL as the preferred modality in the treatment of medium-sized $(<20 \mathrm{~mm})$ upper urinary tract stones $(6,7)$. The literature revealed no study on experienced endourologists with this guideline recommendation despite the decreasing trend of ESWL application, especially in the last 2-3 decades.

The study aimed to evaluate the practice of ESWL treatment from different aspects (indications, technical, and equipmentrelated characteristics) using a questionnaire for the experienced endourologists in the European centers.

\section{Materials and Methods}

Since it is a survey study, it does not require ethics committee approval. This prospective descriptive study was conducted according to the principles of the World Medical Association Declaration of Helsinki's "Ethical Principles for Medical Research Involving Human Subjects." No question was asked regarding the personal data of patients in the survey, thus obtaining informed consent from the centers was not considered.

A survey that was consisting of certain questions about the current trends with ESWL treatment was conducted using the web-based Survey-Monkey system. Survey questions were prepared by our team and mailed to 200 endourologists (addresses were derived from the EAU Section of Urolithiasis database system) in an electronic environment. A recall mail message was sent to all participant endourologists after 1 month following the first mail message from January to March 2016. The survey questionnaire preparation was aimed to evaluate some technical details that could not be given in the guides. The survey was prepared based on the EAU Guidelines. A total of 72 questions on four main topics were constructed to evaluate the demographics of technical equipment, treatment applications, pretreatment preparations, and anesthesia.

\section{Statistical Analysis}

All data from the Survey-Monkey system presented as frequencies of the responses. Only the response rates given to the questions from the Survey-Monkey system were given to us. Therefore, performing advanced statistical analysis was impossible as there was no data suitable for making separate statistics and grouping. This can be considered as the major study limitation.

\section{Results}

The examination of answers to the questionnaire revealed that European endourologists showed an approach following the guidelines.

The most remarkable and significant questions in our survey were presented with tables, including the response rate of each. Table 1 shows the ESWL approaches according to the demographics and history of patients, Table 2 the ESWL approaches for pretreatment preparations and anesthesia, and Table 3 the important questions and answers about ESWL options and approaches.

A total of 97 endourologists (48.5\%) participated in the survey, of whom 75\% were from university or training hospitals and 69\% did have an experience period of $>10$ years in urology (Figure 1). Of them, 74\% have direct access to ESWL-device at their department unit, of which the electromagnetic source-based units were the most common ones. Regarding the treatment responsibility, endourologists were conducting the management in the SWL unit in $61 \%$ of cases and technicians trained on SWL

Table 1. ESWL approaches according to the demographics and history of patients, including the response rate of each question

\begin{tabular}{|c|c|c|c|}
\hline Question & Yes $(\%)$ & No $(\%)$ & Response rate (\%) \\
\hline Do you apply ESWL in appropriately-sized stones as the first option in anomalous kidneys? & 50 & 50 & 43 \\
\hline Do you apply ESWL for appropriately-sized stones as the first option in obese cases? & 38 & 62 & 43 \\
\hline Does the gender of the case affect your decision for ESWL? & 9 & 91 & 43 \\
\hline Does the socio-cultural status of the case affect your decision for ESWL? & 25 & 75 & 42 \\
\hline Do the comorbidities present (hypertension, diabetes mellitus, etc.) affect your decision for ESWL? & 58 & 42 & 42.5 \\
\hline Does the use of anticoagulants affect your decision for ESWL? & 90 & 10 & 43 \\
\hline Does the presence of a solitary functioning kidney affect your decision for ESWL? & 88 & 12 & 43 \\
\hline
\end{tabular}


conducted the treatment in 25\% of cases. Both fluoroscopy and ultrasonography were used to capture an image and focus the stone in 66\% of the participating centers; however, fluoroscopy alone was used in 33\% and ultrasonography alone in 1\%. A regular control for radiation exposure was performed in 78\% of the centers and $86 \%$ had special radiation isolation using radiation protective equipment. Only $26 \%$ of the centers reported the use of a specially designed gel without air bubbles, which were causing problems for effective contact, whereas
$71 \%$ used conventional gel. The majority of the responding urologists (85\%) did not use any special maneuver or approach for coupling.

Most of the participants (78\%) confirmed that ESWL is a minimally invasive treatment modality and $61 \%$ made their decisions according to the EAU guidelines (Figure 2). Informed consent for ESWL was used in a very common manner (88\%); however, $6 \%$ never used a consent form before the treatment and $6 \%$ did not answer this question. Of the endourologists

\begin{tabular}{|l|l|l|l|l|}
\hline Table 2. ESWL approaches for pretreatment preparations and anesthesia & Yes (\%) & No (\%) & If necessary (\%) & Response rate (\%) \\
\hline Question & 36 & 25 & 39 & 38 \\
\hline Do you perform pre-medication for patients' anxiety? & 48 & 26 & 26 & 36,5 \\
\hline $\begin{array}{l}\text { Do you monitor your patients during and immediately after ESWL for } \\
\text { hemodynamic changes? }\end{array}$ & 20 & 45 & 35 & 37,5 \\
\hline Do you apply prophylactic antibiotics before ESWL? & $\mathbf{7 4}$ & 26 & -- & 36,5 \\
\hline $\begin{array}{l}\text { Do you accept ESWL as a "cost-effective modality" when you consider all available } \\
\text { minimally invasive alternatives for stone management? }\end{array}$ & & & & 36,5 \\
\hline $\begin{array}{l}\text { Regarding the social insurance concept of your country, do you accept ESWL as a } \\
\text { reasonable and logical alternative? }\end{array}$ & $\mathbf{8 8}$ & 12 & -- & \\
\hline ESWL: Extracorporeal shockwave lithotripsy & & & \\
\hline
\end{tabular}

\begin{tabular}{|c|c|c|c|}
\hline Question & & $\%$ & $\begin{array}{l}\text { Response } \\
\text { rate }(\%)\end{array}$ \\
\hline \multirow[t]{2}{*}{$\begin{array}{l}\text { What policy for ESWL has impacted the upper ureteral } \\
\text { calculi? }\end{array}$} & The first option, if unsuccessful then URS & 23 & \multirow[t]{2}{*}{37.5} \\
\hline & URS as the first option & 76 & \\
\hline \multirow[t]{2}{*}{$\begin{array}{l}\text { Which position do you use in ESWL in lower ureteral } \\
\text { stones? }\end{array}$} & Prone & 48 & \multirow[t]{2}{*}{33} \\
\hline & Supine & 33 & \\
\hline \multirow[t]{2}{*}{ How do you adjust the level of energy during treatment? } & I begin with a lower level of energy and increase gradually & 87 & \multirow[b]{2}{*}{34.5} \\
\hline & $\begin{array}{l}\text { I change the level of energy depending on the disintegration } \\
\text { level of the stone(s) }\end{array}$ & 9 & \\
\hline \multirow[t]{2}{*}{ When do you evaluate the patient after ESWL? } & $>1$ week later & 45 & \multirow{2}{*}{35.5} \\
\hline & 5-7 days later & 23 & \\
\hline \multirow[t]{2}{*}{$\begin{array}{l}\text { Which radiologic method do you use to evaluate your } \\
\text { patient after ESWL? }\end{array}$} & Kidney ureter bladder radiography & 63 & \multirow[t]{2}{*}{36.5} \\
\hline & Ultrasonography & 22 & \\
\hline \multirow[t]{2}{*}{ What is your definition of "SUCCESS" after ESWL? } & Clinically insignificant residual fragments & 58 & \multirow{2}{*}{37} \\
\hline & Completely stone-free status without any fragment & 42 & \\
\hline \multirow[t]{2}{*}{$\begin{array}{l}\text { What is the meaning of clinically insignificant residual } \\
\text { fragments? }\end{array}$} & $\leq 3 \mathrm{~mm}$ & 41 & \multirow{2}{*}{36.5} \\
\hline & $\leq 2 \mathrm{~mm}$ & 27 & \\
\hline \multirow[t]{2}{*}{$\begin{array}{l}\text { What is the period for you to define the status of success } \\
\text { after ESWL? }\end{array}$} & 3 months & 41 & \multirow[t]{2}{*}{38} \\
\hline & 1 month & 38 & \\
\hline \multirow[t]{2}{*}{$\begin{array}{l}\text { Which radiologic method do you prefer to perform in } \\
\text { children before ESWL? }\end{array}$} & Ultrasonography & 47 & \multirow[t]{2}{*}{33} \\
\hline & Low dose CT & 25 & \\
\hline
\end{tabular}


without ESWL unit in their hospital, 72\% reported sending the patients for ESWL to another hospital, whereas 28\% of them tended to treat the stone(s) with another minimally invasive modality, wherein flexible ureteroscopy $(81 \%)$ was the most commonly performed procedure (Table 1). In addition to the renal collecting system anatomy, stone-related factors (size, location, density, and chemical composition) were the main parameters considered for the decision-making of ESWL. More than half of the endourologists (54\%) assessed the stone burden by measuring the longitudinal axis of the stone and stone volume as the second approach (27\%). Most of the endourologists reported using ureteral stenting before ESWL for solitary functioning kidneys (always 33\%, if the stone is $>1.5$ $\mathrm{cm} ; 29 \%), 27 \%$ of them were found not to routinely place any stent, and $13 \%$ did not respond to this question. Stone density has been used for ESWL indication and 71\% of endourologists accepted $<1000$ hounsfield unit as a cut-off value for stone hardness to perform ESWL (Figure 3).

Most of the endourologist (83\%) evaluated urinary tract infection status and $62 \%$ were in favor of completely stopping the anticoagulant medication before ESWL. No special bowel preparation was done by $62 \%$ of participants, whereas $38 \%$ recommended feeding with aqueous food or laxative agent. Nonsteroidal anti-inflammatory drugs (NSAIDs) (58\%) were the most commonly used analgesics before ESWL. Pediatric ESWL was performed under either general anesthesia or Sedoanalgesia (depending on the age of the child) by the majority of

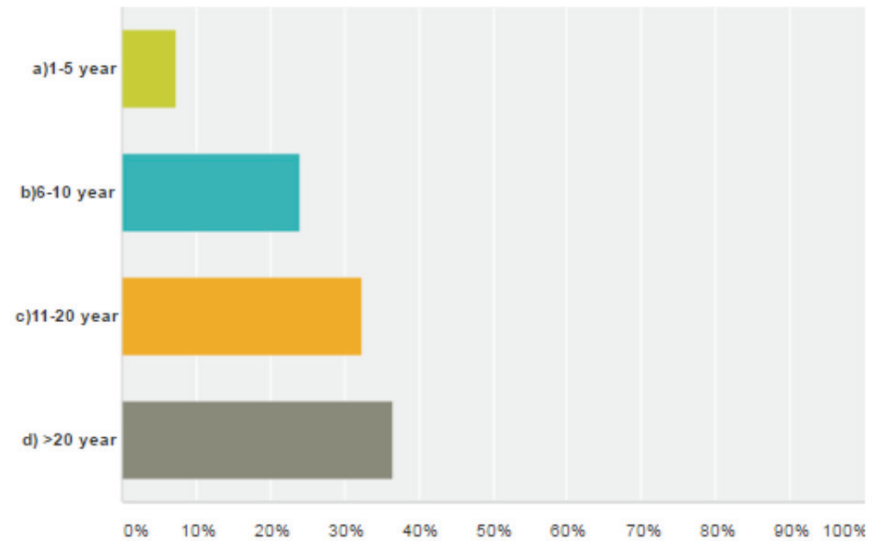

Figure 1. Experience period of European endourologists

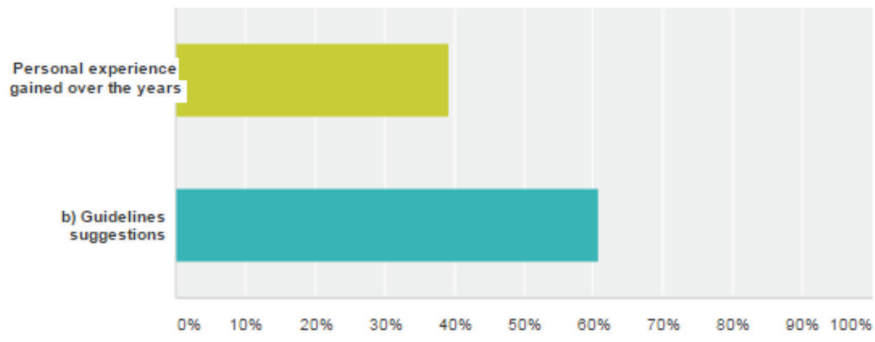

Figure 2. Guidance in treatment modality decision the endourologists (58\%); however, $42 \%$ did not perform ESWL for children. A maximum number of sessions was reported as 2 and 3 sessions and rates were $43 \%$ and $45 \%$, respectively (Figure 4). The delivery rate of SW number/min was reported as 90 and $60 \mathrm{SW} / \mathrm{min}$ by $50 \%$ and $47 \%$ of the responders, respectively. The maximum number of SW in one session for adults were 3000 (33\%), 3500 (21\%), 4000 (18.5\%), 2000 (13\%), and 1000 (10\%), respectively, and $2000(38 \%), 1500(25 \%), 1000(10 \%)$, and $500(10 \%)$, respectively, in children. The most preferred period between the two sessions was $>10$ days, with rates of $46 \%$ in kidney stones and 30\% in ureteral stones. Increased oral hydration and medical expulsive treatment (MET) were commonly recommended after SWL sessions. Routine antibiotic prophylaxis was not used by most endourologist (45\%), and ureteroscopy (39\%) was the most commonly applied approach after steinstrasse formation (Tables 2 and 3 ).

Unfortunately, the Survey-Monkey system did not let us know who or what country the respondents were from. This is another limitation of this study. However, we know that the vast majority of people whose e-mail addresses were given were from central, southern, and eastern Europe.

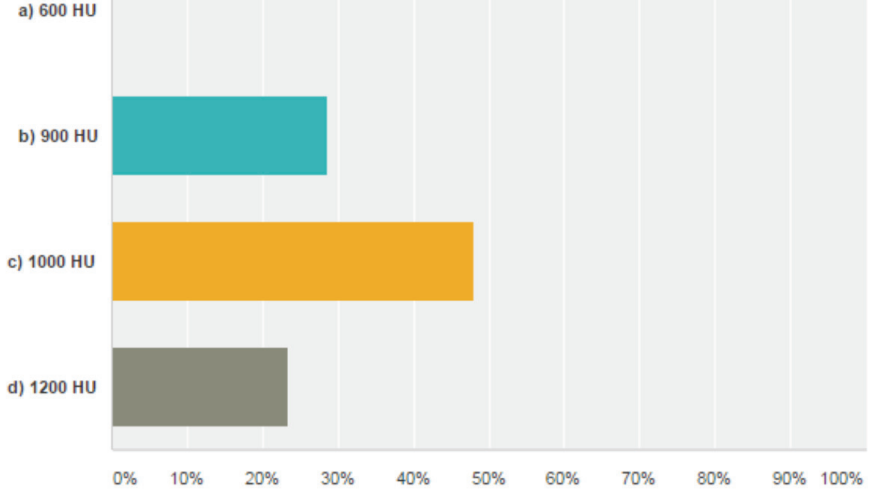

Figure 3. Cut-off value for stone density before ESWL

ESWL: Extracorporeal shockwave lithotripsy

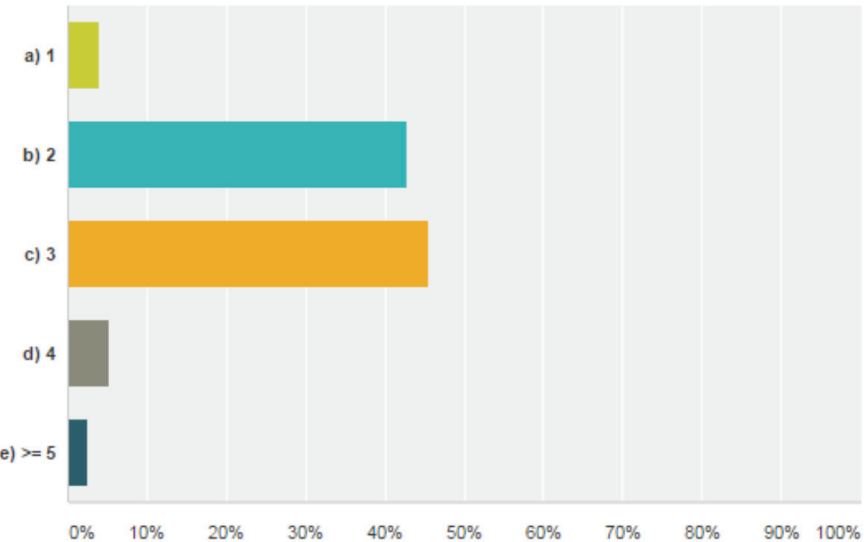

Figure 4. Maximum number of sessions for the same stone 


\section{Discussion}

The response rate of this survey was $33-48.5 \%$, which seems similar or higher than such studies reported thus far $(2,8-10)$. All survey-based studies were mainly performed on a national platform and evaluated urinary tract stone management in general. Our study is the first that aimed to investigate ESWL trends and treatments for upper urinary tract stones in an international-based manner by including different European countries. Similar to our study, Lantz et al. (11) reported the comparative evaluation of ESWL practice in American and Canadian endourologists in 2016 and Sharma et al. (12) reported data of phone call-based survey from 21 different centers in the United Kingdom.

Regarding the ESWL practice in a special group of cases, most of the respondents (62\%) do not use ESWL in patients with obesity with appropriate size stones, and 50\% have applied ESWL as the first option in anomalous kidneys (Table 1). The EAU guidelines state that ureteroscopy is a better and safe procedure for the management of renal stones in patients with obesity (6). Passage of fragments after ESWL might be poor in horseshoe kidneys; therefore, ureteroscopy was prioritized in patients with obesity and skeletal malformations or anomalies.

Solitary functioning kidney is an important factor for ESWL treatment decision, which was emphasized in our survey with an $88 \%$ rate (Table 1). Our survey results revealed that $33 \%$ of participants placed a JJ stent in all cases, whereas 27\% used stenting in patients with large-sized stones in solitary kidneys. Lantz et al. (11) demonstrated that 51\% of Canadian urologists reported stenting the patients with solitary kidneys in a routine manner, whereas $66 \%$ of American urologists did routinely place a stent, suggesting that Canadian and American urologists are more cautious than European urologists. Medico-legal problems may be another reason for this approach in North America.

Our survey revealed that $62 \%$ of participants completely discontinued the anticoagulant treatment before ESWL. Low dose acetylsalicylic acid was not specifically stated in our question, thus it could be assumed that anticoagulant treatment meant covering low dose acetylsalicylic acid. Related to this issue, this rate was significantly higher for American urologists, where they tended to stop acetylsalicylic acid both for renal and ureteral stones (96\% and 90\%, respectively) when compared with Canadian urologists (88\% and 62\%, respectively) (10). The 2018 EAU Guidelines and American Urology Association (AUA) Guidelines on the temporary discontinuation or bridging of antithrombotic therapy in high-risk patients should be discussed with the internist $(6,13)$. A published study evaluating the perinephric hematoma formation in patients with ESWL for renal and proximal ureteric stones reported the anticoagulant/ antiplatelet medications as well as intraoperative hypertension to be significant risk factors (14). The rate of perirenal hematoma was lower (0.34\%) in Razvi et al.'s (14) study compared to other series. However, our study results revealed that only low dose acetylsalicylic acid $(81 \mathrm{mg})$ and nonsteroidal anti-inflammatory drugs were continued before ESWL while warfarin, heparin, dipyridamole, clopidogrel, and ticlopidine were discontinued. Anticoagulant/antiplatelet medications were found as a significant risk factor for perinephric hematoma (hazard ratio: 4.198). Another study reported that perirenal hematoma occurred in $0.53 \%$ of patients, of which $0.23 \%$ were only clinically symptomatic. All patients who had perirenal hematoma were reported using medication for cardiovascular diseases, but in this study low dose $(100 \mathrm{mg})$ acetylsalicylic acid intake did not influence the perirenal hematoma (15). Another recent study reported similar rates for perirenal hematoma after ESWL (16). Razvi et al. (14) revealed the model of the ESWL machine. However, our study did not evaluate the different ESWL models, thus we could not comment on this issue.

Antibiotic prophylaxis is not used by most of the endourologists $(45 \%)$ in our survey. The American urologists reported high rates of prophylactic antibiotic usage (78\%); however, this rate was significantly low among the Canadian urologists, which was reported in $2 \%$ of the cases. Interestingly, both groups of urologists reported similar rates for the performance of routine urine culture examination (11). However, both EAU and AUA guidelines do not recommend routine use of antibiotics before ESWL $(6,17)$. Our study revealed that $20 \%$ performed routine, antibiotic usage, which reflects the European approach as Sharma et al. (12) with 25\% from the United Kingdom. Both guidelines recommend using prophylactic antibiotics in case of any suspicion of urinary tract infection. Our survey did not evaluate the ESWL application to patients with nephrostomy tubes but recommended to use of intravenous prophylactic antibiotics before ESWL in patients with the increased bacterial burden $(6,7)$.

Our study revealed that NSAIDs (58\%) is the most commonly used analgesics before ESWL, which is similar to Sharma et al. (12), and diclofenac was the most frequently used agent. The EAU guidelines recommend controlling pain during the ESWL procedure to limit pain-related movements for precise and successful targeting (6). Of the American urologists, $8 \%$ routinely used general anesthesia during ESWL, whereas only 5\% among the Canadian urologists (11). Higher ESWL treatment success rates were reported with general anesthesia than intravenous sedation application; however, our institute does not routinely use general anesthesia for ESWL except for children (18). A recent review reported that simple analgesics, NSAIDs, and opioids could all reduce the pain that is associated with ESWL to a tolerated level. No compelling differences were revealed in the safety or efficacy of simple analgesics and NSAIDs; however, 
analgesia was more often described as adequate for opioids than NSAIDs (19). Our study reported opioid usage in $21.6 \%$ of respondents.

MET was routinely used in 38\% of cases and 39\% of cases with larger fragments in our survey. Sharma et al. (12) reported using MET in 20\% of the renal stone cases and 15\% of ureteric stones after ESWL. The EAU Guidelines recommend using MET after ESWL for renal and ureteric stones to increase stone-free rates and reduce analgesic requirements (6). Our results demonstrated the highest application rates of MET than the previous reports in the literature.

The delivery rate of shock waves using 90 and $60 \mathrm{SW} / \mathrm{min}$ was reported in $50 \%$ and $47 \%$ of respondents, respectively. Other meta-analyses confirmed that ESWL efficacy could be improved with slower SW application rates, with approximately 50\% significantly reduced costs (20-22). Of the Canadian urologists, $76 \%$ reported using a high SW delivery rate (120/min), and the American urologists reported similar SW rates with our results as 45\% for $60 \mathrm{SW} / \mathrm{min}$ and $41 \%$ for $90 \mathrm{SW} / \mathrm{min}$ (11). Compatible with the EAU guidelines, our study revealed that $3 \%$ of participants use $120 \mathrm{SW} / \mathrm{min}$. The EAU guidelines pointed out that tissue damage increased with an increased SW rate (6). The maximum number of SW in one session for adults was 3000 in our survey, which was similar to both the Canadian and American urologists (11).

Proper acoustic coupling is recommended by the EAU guidelines since the air bubbles were not eliminated effectively during the acoustic coupling, which significantly decreases the delivery of SW energy and deflects 99\% of SW as previously reported $(6,23,24)$. Our study revealed that $26 \%$ of the participants reported using special gels whereas the others (71\%) used normal ultrasonography gel $(6,24)$.

Our study revealed that $48 \%$ preferred the prone position as the most preferred position for distal ureteral stones. However, Kamel et al. (25) revealed a higher stone-free rate for the supine transgluteal position compared with the prone position. Other studies supported and revealed successful results in supine transgluteal position for the distal ureteral stones with ESWL $(26,27)$.

\section{Study Limitations}

Our study is the first one that reflected the European treatment trends and technical equipment of ESWL; however, it has some certain limitations. First, our survey had so many questions and this relatively time-consuming format could lower the response rates of the questionnaire. Additionally, a recall mail message was sent to all participants after 1 month following the first one. The participation rate could have been higher with more than one recall mail. However, our study is valuable because it is the first study on ESWL to reflect the approaches of experienced endourologists in Europe.

\section{Conclusion}

Data obtained from our study revealed that most experienced European endourologist make their treatment decisions according to the EAU guideline. ESWL is still preferred in the treatment of symptomatic urinary stones by the majority of our respondents. The literature review revealed no publication similar to this study from Europe.

\section{Ethics}

Ethics Committee Approval: Since it is a survey study, it does not require ethics committee approval.

Informed Consent: No question was asked regarding the personal data of patients in the survey, thus obtaining informed consent from the centers was not considered.

Peer-review: Externally peer-reviewed.

\section{Authorship Contributions}

Surgical and Medical Practices: S.Y., C.E., Y.E.K., H.H.T., Concept: S.Y., C.E., Y.E.K., Ö.Y., Design: S.Y., C.E., Y.E.K., Ö.Y., Data Collection or Processing: S.Y., C.Y., Y.E.K., H.H.T., Analysis or Interpretation: S.Y., C.Y., Y.E.K., H.H.T., Literature Search: S.Y., C.Y., Y.E.K., H.H.T., Writing: S.Y., C.E., M.P., Y.E.K., H.H.T., Ö.Y.

Conflict of Interest: No conflict of interest was declared by the authors.

Financial Disclosure: The authors declare that they have no relevant financial.

\section{References}

1. Sorokin I, Mamoulakis C, Miyazawa K, Rodgers A, Talati J, Lotan Y Epidemiology of stone disease across the world. World J Urol 2017;35:13011320.

2. Yildirim K, Olcucu MT, Colak ME. Trends in the treatment of urinary stone disease in Turkey. PeerJ 2018;6:e5390.

3. Heers H, Turney BW. Trends in urological stone disease: a 5-year update of hospital episode statistics. BJU Int 2016;118:785-789.

4. Srisubat A, Potisat S, Lojanapiwat B, Setthawong V, Laopaiboon M. Extracorporeal shock wave lithotripsy (ESWL) versus percutaneous nephrolithotomy (PCNL) or retrograde intrarenal surgery (RIRS) for kidney stones. Cochrane Database Syst Rev 2014:CD007044.

5. Junbo L, Yugen L, Guo J, Jing H, Ruichao Y, Tao W. Retrograde Intrarenal Surgery vs. Percutaneous Nephrolithotomy vs. Extracorporeal Shock Wave Lithotripsy for Lower Pole Renal Stones 10-20 mm : A Meta-analysis and Systematic Review. Urol J 2019;16:97-106.

6. Türk C, Neisius AA, Petrik A, Seitz C, Skolarikos KTA, Guidelines Associates: J.F. Donaldson TD, N. Grivas YR; EAU Guidelines on Urolithiasis. 2018.

7. Chaussy CG, Tiselius HG. How can and should we optimize extracorporeal shockwave lithotripsy? Urolithiasis 2018;46:3-17. 
8. Ates F, Zor M, Yılmaz O, Tuncer M, Ozturk M, Gurbuz C, Atis G, Koca O, Yildirim A, Eryildirim B, Kucuk EV, Narter F, Senkul T, Sarica K. Management behaviors of the urology practitioners to the small lower calyceal stones: the results of a web-based survey. Urolithiasis 2016;44:277-281.

9. Schnabel MJ, Brummeisl W, Burger M, Rassweiler JJ, Knoll T, Neisius A, Chaussy CG, Fritsche HM. Stoßwellenlithotripsie in Deutschland: Ergebnisse einer deutschlandweiten Umfrage [Shock wave lithotripsy in Germany: Results of a nationwide survey]. Urologe A 2015;54:1277-1282.

10. Proietti S, Somani BK, Pietropaolo A, Saitta G, Rodríguez-Socarrás ME, Rosso M, Bellinzoni P, Gaboardi F, Giusti G. Italian endourological panorama: results from a national survey. Cent European J Urol 2018;71:190-195.

11. Lantz AG, McKay J, Ordon M, Pace KT, Monga M, Honey RJ. Shockwave Lithotripsy Practice Pattern Variations Among and Between American and Canadian Urologists: In Support of Guidelines. J Endourol 2016;30:918-922.

12. Sharma NL, Alexander CE, Grout E, Turney BW. Shock-wave lithotripsy: variance within UK practice. Urolithiasis 2017;45:193-201.

13. Culkin DJ, Exaire EJ, Green D, Soloway MS, Gross AJ, Desai MR, White JR, Lightner DJ. Anticoagulation and antiplatelet therapy in urological practice: ICUD/AUA review paper. J Urol 2014;192:1026-1034.

14. Razvi $H$, Fuller $A$, Nott $L$, Méndez-Probst CE, Leistner R, Foell $K$, Davé $S$, Denstedt JD. Risk factors for perinephric hematoma formation after shockwave lithotripsy: a matched case-control analysis. J Endourol 2012;26:1478-1482.

15. Schnabel MJ, Gierth M, Chaussy CG, Dötzer K, Burger M, Fritsche HM. Incidence and risk factors of renal hematoma: a prospective study of 1,300 SWL treatments. Urolithiasis 2014;42:247-253.

16. El-Nahas AR, Taha DE, Elsaadany MM, Zahran MH, Hassan M, Sheir KZ. Hospital admission for treatment of complications after extracorporeal shock wave lithotripsy for renal stones: a study of risk factors. Urolithiasis 2018;46:291-296.

17. Assimos $D$, Krambeck $A$, Miller NL, Monga $M$, Hassan $M$, Nelson CP, Pace KT, Pais VM, Pearle MS, Preminger GM, Razvi H, Shah O, Matlaga BR. Surgical Management of Stones: AUA/Endourology Society Guideline (2016). AUA/ Endourological Society Guideline: Published 2016.
18. Sorensen C, Chandhoke P, Moore M, Wolf C, Sarram A. Comparison of intravenous sedation versus general anesthesia on the efficacy of the Doli 50 lithotriptor. J Urol 2002;168:35-37.

19. Aboumarzouk $O M$, Hasan $R$, Tasleem $A$, Mariappan $M$, Hutton $R$, Fitzpatrick J, Beatty L, Jones GE, Amer T. Analgesia for patients undergoing shockwave lithotripsy for urinary stones - a systematic review and meta-analysis. Int Braz J Urol 2017;43:394-406.

20. Li K, Lin T, Zhang C, Fan X, Xu K, Bi L, Han J, Huang H, Liu H, Dong W, Duan $Y, Y u M$, Huang J. Optimal frequency of shock wave lithotripsy in urolithiasis treatment: a systematic review and meta-analysis of randomized controlled trials. J Urol 2013;190:1260-1267.

21. Semins MJ, Trock BJ, Matlaga BR. The effect of shock wave rate on the outcome of shock wave lithotripsy: a meta-analysis. J Urol 2008;179:194197.

22. Koo V, Beattie I, Young M. Improved cost-effectiveness and efficiency with a slower shockwave delivery rate. BJU Int 2010;105:692-696.

23. Pishchalnikov YA, Neucks JS, VonDerHaar RJ, Pishchalnikova IV, Williams $J C J r$ McAteer JA. Air pockets trapped during routine coupling in dry head lithotripsy can significantly decrease the delivery of shock wave energy. J Urol 2006;176:2706-10.

24. Jain A, Shah TK. Effect of air bubbles in the coupling medium on efficacy of extracorporeal shock wave lithotripsy. Eur Urol 2007;51:1680-1687.

25. Kamel M, Salem EA, Maarouf $A$, Abdalla M, Ragab A, Shahin AM. Supine transgluteal vs prone position in extracorporeal shock wave lithotripsy of distal ureteric stones. Urology 2015;85:51-54.

26. Galli R, Sighinolfi MC, Micali S, Martorana E, Rosa M, Mofferdin A, Bianchi G. Advantages of the supine transgluteal approach for distal ureteral stone extracorporeal shock wave lithotripsy: outcomes based on CT characteristics. Minerva Urol Nefrol 2017;69:189-194.

27. Choo MS, Han JH, Kim JK, Shin TY, Lee WK, Lee SK, Lee SH. The transgluteal approach to shockwave lithotripsy to treat distal ureter stones: a prospective, randomized, and multicenter study. World J Urol 2018;36:1299-1306. 